\title{
Experimental Examination of an Axial Compressor as a Basis for an Active Stall Avoidance System*
}

\author{
RICHARD SCHULZE ${ }^{a, \dagger}$, DIETMAR K. HENNECKE $^{a},{\text { THUYEN } \text { LE }^{\mathrm{b}} \text { and MANFRED GLESNER }}^{\mathrm{b}}$ \\ ${ }^{\mathrm{a}}$ Department of Gas Turbines and Flight Propulsion, Petersenstr. 30, ${ }^{\mathrm{b}}$ Institute of Microelectronic Systems, Karlstr. 15; \\ Darmstadt University of Technology D-64287 Darmstadt, Germany
}

(Received 8 May 1998; In final form 16 July 1998)

\begin{abstract}
A single-stage subsonic compressor was examined with respect to compressor instabilities. During the inception of rotating stall, the transients of the pressure rise and mass flow were measured as well as their hysteresis. The development of the stall cell and the characteristics of the unstable operating range were determined.

Several measurement techniques and data analysis methods for the real-time detection of unstable compressor operation and aspects of their implementation on a digital signal processor are discussed.

The results of the work are meant to serve as a basis for the design of an active stall avoidance system.
\end{abstract}

Keywords: Compressor instabilities, Post-stall transients, Stall detection, Real-time

\section{INTRODUCTION}

Presently, engine stall is one of the most challenging problems in the evolution process of gas turbines. It is caused by unstable flow conditions in the engine's compressor unit. Engine stall is avoided by forbidding operation in ranges that are critical in terms of compressor instabilities. This in turn reduces the engine performance and/or increases the weight.

The passive avoidance strategy causes a conflict between the demand for more efficient engines on the one hand and safe engine operation on the other hand. Inclusion of active stall control methods into the engine control system may be one way to solve the conflict.

A control system is under development which shall allow the safe operation of a turbo compressor close to its stability line. Compressor stall caused by transient inlet distortions shall be actively suppressed in such a manner that the compressor's operating regime varies as little as possible. With respect to the design of such a control system, the following questions are addressed:

1. How do instabilities develop in the
compressor?

\footnotetext{
* This paper was originally presented at ISROMAC-7.

${ }^{\dagger}$ Corresponding author. Tel.: 06151 16-2150. Fax: 06151 16-2159. E-mail: rich@gfa.tu-darmstadt.de.
} 
2. Where can compressor instabilities be seen first and how can unstable compressor operation be identified as early as possible?

3. How do the results affect the design of the control system?

\section{EXPERIMENTAL SETUP}

Figure 1 gives an overview of the compression system configuration. The compressor and a downstream throttle (A) are located in an inlet duct which is connected to a plenum. The plenum discharges into an exit duct with a dynamic throttle (B). Figure 2 depicts the compressor with the inlet duct, the diffuser, and the downstream throttle A which was used for the experiments. The test stand can be seen in Fig. 3. Table I gives a brief overview of the compressor data. Figure 4 shows the characteristic for a rotor speed of $3700 \mathrm{rpm}$ at which the experiments were carried out. Figure 5 depicts the circumferential (1-8) and axial (A-D)

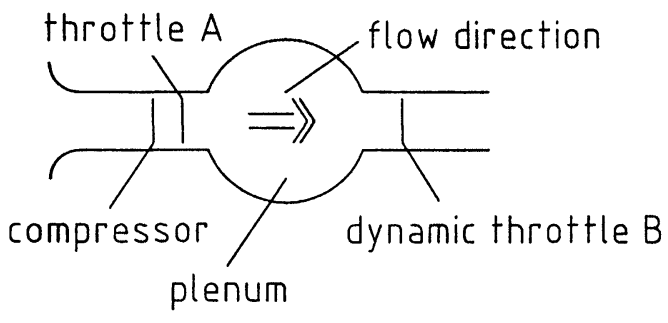

FIGURE 1 Sketch of the experimental setup for the control system.

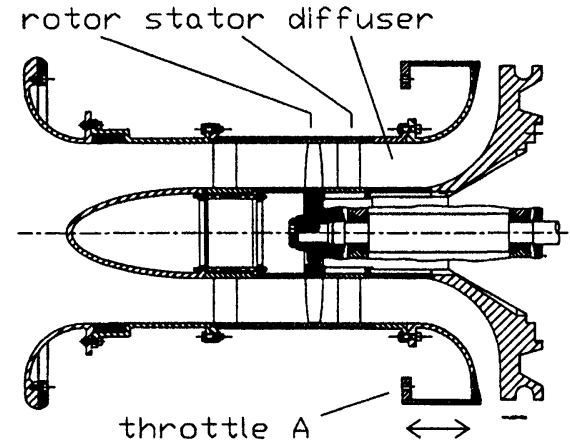

FIGURE 2 Cross section of the compressor.

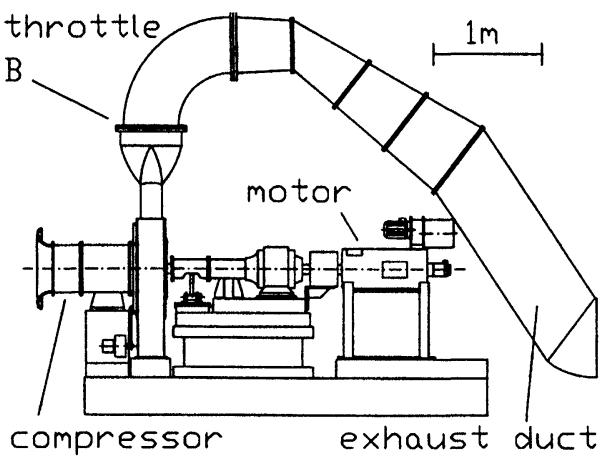

FIGURE 3 Overview of the test stand.

TABLE I Compressor data
Configuration:

No. of blades:

Blade sections:

Hub-to-pip ratio:

Tip diameter:

Speed (max):
Axial: rotor, stator 24,27

NACA 65, DCA

0.56

$0.4 \mathrm{~m}$ $7000 \mathrm{rpm}$

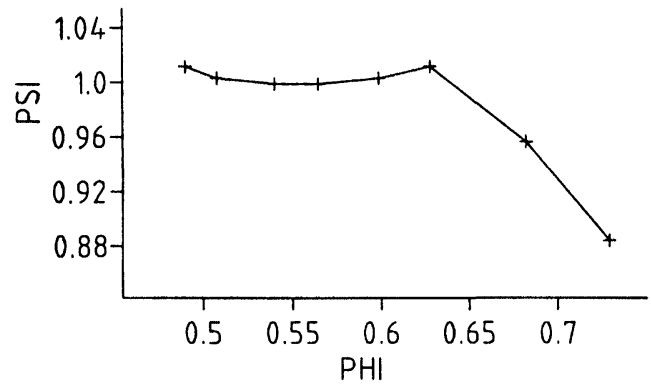

FIGURE 4 Compressor characteristic at $n=3700 \mathrm{rpm}$.
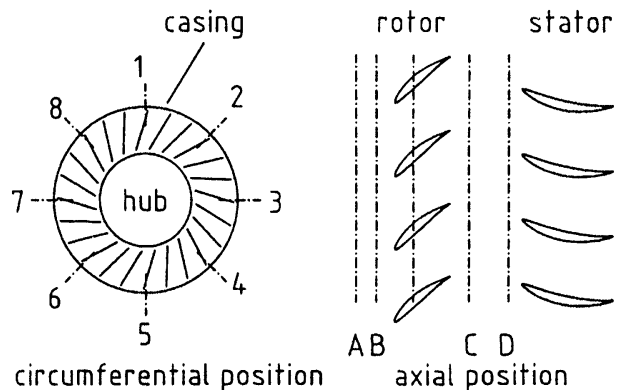

FIGURE 5 Probe locations. 
locations of the sensors. The traversing probes were moved radially from hub to shroud. For the determination of the compressor map, five-hole probes were traversed at the locations $\mathrm{A} 6$ and $\mathrm{C} 4$ (see Fig. 5).

Two different kinds of piezo-resistive semiconductor sensors were used for dynamic pressure measurements (see Fig. 6). Surface-mounted sensors were used for the probe type I and type II. They provide high frequency response. However, they are costly and difficult to handle. A sensor configuration as shown in position III of Fig. 6 was applied for dynamic wall static pressure measurements in addition to the type-II sensors. Their maximum response frequency is about $1 \mathrm{kHz}$ at a significantly lower price and easier handling. The applicability of the type-III sensors in the control system was compared to that of the type-II sensors.

A microphone was mounted $0.5 \mathrm{~m}$ upstream of the compressor intake to allow the compressor sound to be analysed.

\section{MEASUREMENT RESULTS AND DISCUSSION}

The measurements were performed in three operating modes:

1. During stable operation it was examined whether flow phenomena can be found that indicate the approach of the stability line before the onset of compressor stall.

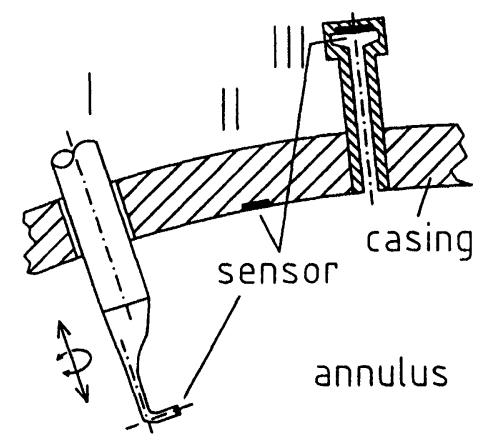

FIGURE 6 Schematic view of the dynamic pressure probes.
2. The compressor behaviour was examined during the transient from stable to unstable operation.

3. The modes of unstable operation and the characteristics for each mode were determined as a prerequisite for modelling the compressor.

\section{Stable Operation}

The speed line of the stable operating mode can be seen in Fig. 4. The relative minimum of the pressure rise at $\Phi=0.11$ is explained in Wang and Hennecke (1994). Flow separation in the rotor at mid-span leads to the reduction of the pressure rise when the mass flow is reduced below $\Phi=0.63$. They are stable thus allowing an increasing pressure rise at mass flow rates below $\Phi=0.55$.

Dynamic measurements in the rotor wake were taken to obtain data for the real-time identification of the operating point (cf. Koenig et al., 1992; Wang et al., 1993;1994;1995; Windirsch 1995). However, since non-intrusive measurement techniques are preferred for the stall control system, it was examined whether indicators for flow separation during stable operation can be found at the compressor casing. Figure 7 shows the wall static pressure distribution in the vicinity of the rotor. The reference system is fixed to the rotor. Type-II sensors (see Fig. 6) were used for the measurements. No indicators for the flow separation could be seen in the blade tip region. The real-time estimation of the operating point in the stable operating regime cannot make use of the flow separation that is described in Wang
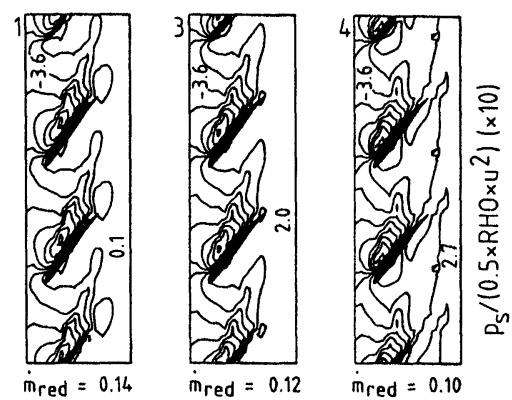

FIGURE 7 Wall static pressure distributions under various operating conditions. 
and Hennecke (1994) when wall static pressure probes are applied.

\section{Transient Operation}

Due to the small volume between the compressor and throttle A as well as the moderate pressure rise, rotating stall is the mode of unstable operation. When the compressor enters the unstable operating regime, part-span stall develops. When the mass flow is further reduced, the compressor goes into full-span stall. In $90 \%$ of the cases the initial number of stall cells is one, otherwise two.

Location of the stall initiation Stall detection in an as-early-as-possible state is most important for the stall control system. The instrumentation of the compressor must be placed where unstable operation can be seen first.

Figure 8 shows the radial location where upcoming stall can be seen first. With a type-I probe (see Fig. 6), the time was determined after which upcoming stall could be seen relative to a type-II sensor located at the casing. Both sensors were mounted in the axial location A (see Fig. 5). The onset of rotating stall can be seen first at the compressor casing. This result is also confirmed by the fact that the initial type of rotating stall is part-span stall in the blade tip region (see Section Unstable Operating Range). At 50\% blade height, rotating stall can be seen earlier, compared to most other radial locations. This believed to be due to the mid-span flow separation which occurs

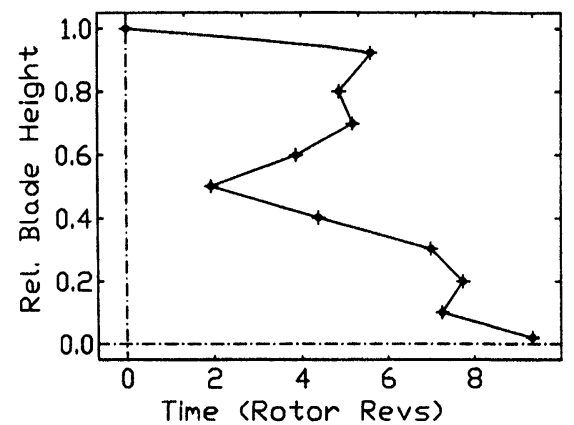

FIGURE 8 Delay of the stall detection at various radial locations. prior to the compressor stall (see Section Stable Operation).

Development of the stall cell A field of typeIII probes (see Fig. 6) in the positions A1-A8 (see Fig. 5) and two type-II probes in the locations B2 and B8 were used to examine the evolution of an upcoming stall cell. Only stall inceptions with a single stall cell were regarded. For 11 stall inceptions the size and the circumferential location of the stall cell during the evolution process were manually extracted from sensor signals as they can be seen in Fig. 21. The time history of the cell size is shown in Fig. 9, and the development of the cell speed in the absolute frame of reference can be seen in Fig. 10. The results indicate that stall develops from a small disturbance which rotates at rotor speed. As it grows it decelerates to approximately $45 \%$ rotor speed in the absolute frame of reference.

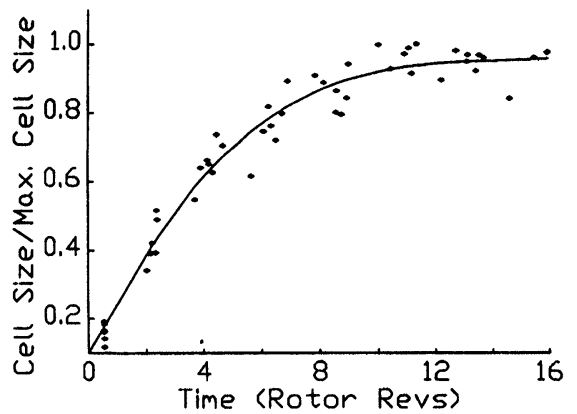

FIGURE 9 Time history of the relative stall cell size after stall initiation.

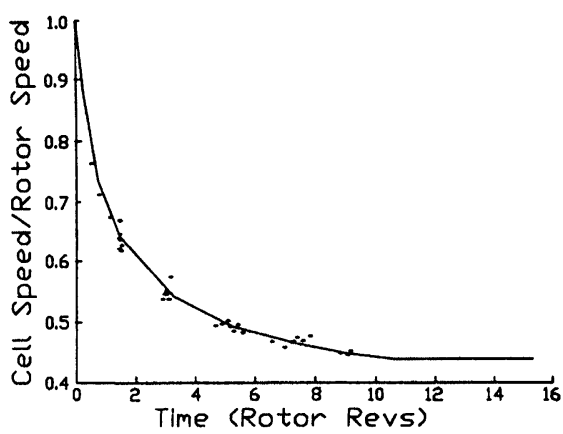

FIGURE 10 Time history of the relative stall cell speed after stall inception. 
Mass flow and pressure rise transients When examining the transients of the mass flow and the pressure rise during stall inception, the probes should be out of reach of the stall cell to avoid erroneous measurement results.

The experimental setup for the mass flow measurements are shown in Fig. 11. The compressor ingests air from a large settling chamber (i.e. the laboratory). The inlet of the settling chamber is a nozzle where a hot-wire anemometer is installed. Assuming incompressibility of the fluid, the velocity in the nozzle is a measure for the instantaneous mass flow through the compressor. The nozzle was kept short in length, and the Mach number in the nozzle throat was kept small. Thus, additional effects due to compressibility and inertia of mass can be neglected.

The transient of the total pressure rise in the compressor was determined by measuring the wall static pressure in the diffuser between the compressor and throttle A. When compressibility effects can be neglected, the static pressure there depends on the total pressure rise in the compressor, the mass flow, and the rate of change of the mass flow.

Figure 12 depicts the measured and the computed (see Section Modelling of the Test Stand) transients of the mass flow and the wall static pressure in the diffuser. Figure 13 shows the measured and the computed hysteresis in mass flow and pressure

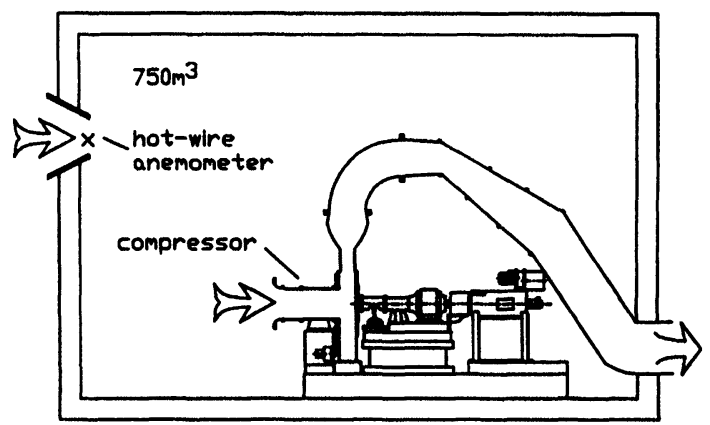

FIGURE 11 Experimental setup for the measurement of the mass flow transient. rise between different operating modes. The hysteresis between stable operation and part-span stall is significant. The hysteresis between part-span stall and full-span stall was found to be small. It was possible to adjust the throttle in a way that the compressor alternated self-acting between the two modes, repeatedly.

For the successful suppression of compressor stall, it is crucial that upcoming stall is identified and the backpressure is adjusted within a time that is well below the development time of the rotating stall (roughly 10 rotor revolutions, see Figs. 9 and $10)$. Only then the variation of the operating point can be kept small.

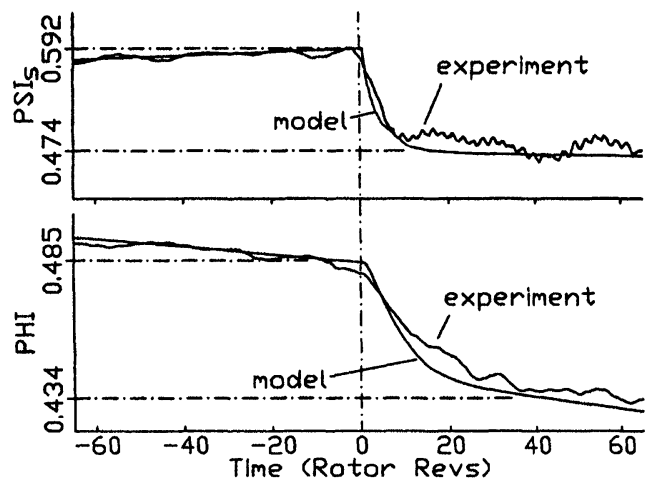

FIGURE 12 Measured and computed mass flow and pressure rise at stall inception.

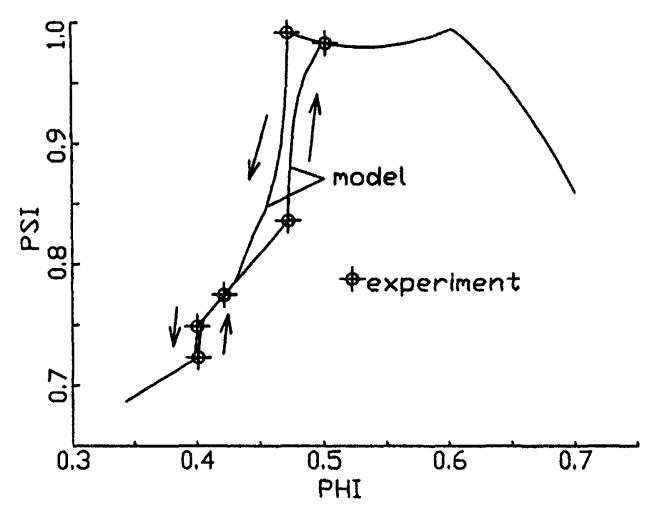

FIGURE 13 Calculated and measured hysteresis between the operating modes. 


\section{Unstable Operating Range}

The measured and the modelled characteristics for both the part-span and the full-span stalls operating regimes are shown in Fig. 14. The mass flow and the pressure rise were determined as described in Section Transient Operation.

In order to obtain an impression of the shape of the fully developed stall cells, a type-I probe was traversed at the location B4 (see Figs. 5 and 6) during both part-span and full-span stalls operation. The signal from a type-II sensor in the same axial location was recorded at the same time. This signal could then be used to create a frame of reference that is fixed to the stall cell thus allowing the circumferential association of the signals from the various radial locations.

Figure 15 shows a section of the annulus with the fully developed part-span and full-span stall cells

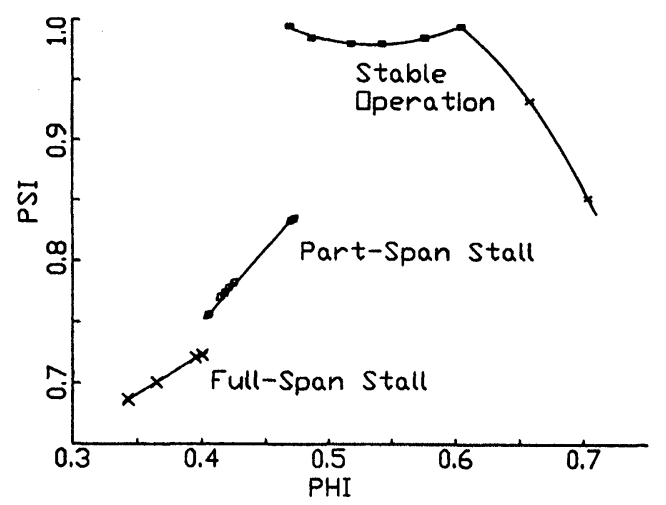

FIGURE 14 Measured and modelled characteristics of the different operating modes.
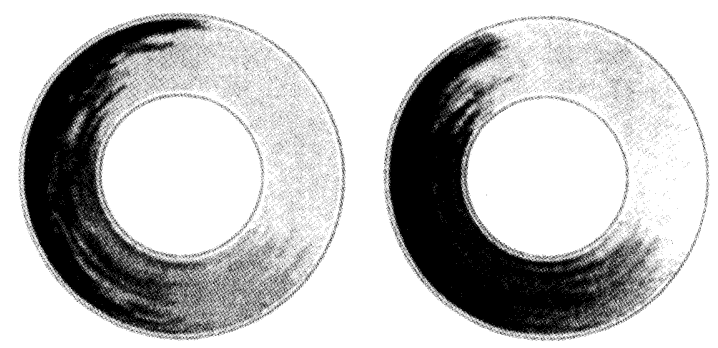

FIGURE 15 Fully developed part-span (left) and full-span (right) stall cell. The direction of rotation in the absolute frame of reference is clockwise. (dark areas). The part-span stall cell rotates at a speed of $44 \%$ of the rotor speed in the absolute frame of reference and the full-span stall cell with $30 \%$ respectively. Quantitative data of the pressure inside the stall cell cannot be provided because the probe is inappropriate for that purpose.

\section{MODELLING OF THE TEST STAND}

For the design of the control system numerical simulation is an efficient way to estimate the behaviour of the test stand, its components, and the controller. A numerical model has to be found that sufficiently represents the important properties of the test stand.

The test stand consists of an inlet duct with the compressor, a plenum, and an exit duct (see Fig. 1). Throttle A (see Figs. 1 and 2 ) is a ring nozzle at the diffuser exit. Throttle B is a dynamic throttle that consists of lamellas which are turned collectively by a step motor thus varying the flow-through area. The throttle pressure drop is approximated as in Greitzer (1976).

The assumptions for the fluid dynamic model of the ducts and the plenum as well as the equations of motion are the same as in Greitzer (1976). When throttle $A$ is used, both ducts and the plenum can be regarded as a single duct because then the potential energy that can be stored in the plenum is negligible.

Pressure losses in the ducts which are not caused by the throttles $\mathrm{A}$ and $\mathrm{B}$ are modelled with additional throttles with constant flow-through area. These throttles are in line with the other components in the ducts (see Fig. 17). The flowthrough areas of the additional throttles were found experimentally.

The compressor model should provide a sufficient representation of the compressor for both steady state and transient operation. The approximation for the transient compressor response in Greitzer (1976) was replaced by a non-linear approximation that was deduced from the experimental data shown in Section Development of the Stall Cell. 
Applying the models shown above, the transients of the compressor pressure rise can be derived from the measured mass flow transients. Together with the compressor characteristics, the transient compressor response was found to be as follows (see also Fig. 16):

$$
\begin{aligned}
\left|\frac{\mathrm{d} \Pi}{\mathrm{d} t}\right|= & 5.5 \cdot 10^{-3} \cdot \sqrt{0.38 \cdot\left|\Pi_{\mathrm{ss}}-\Pi\right|} \\
& +5.2 \cdot 10^{-2} \cdot\left|\Pi_{\mathrm{ss}}-\Pi\right| .
\end{aligned}
$$

The sign of $(\mathrm{d} \Pi / \mathrm{d} t)$ is equal to that of $\left(\Pi_{\mathrm{ss}}-\Pi\right)$.

The complete model of the test stand is shown in Fig. 17. It was applied to simulate the pressure and mass flow transients after stall inception. The results are depicted in Fig. 12 together with the measured data. Figure 13 shows the computed transient compressor mass flow and pressure rise when the operating mode changes between stable and unstable operations, and between part-span and full-span stalls.

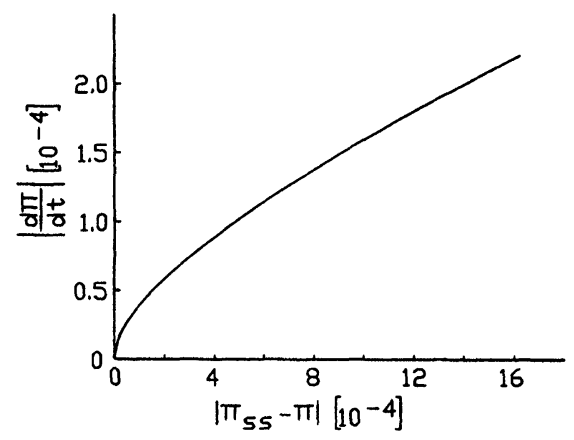

FIGURE 16 Transient compressor response.

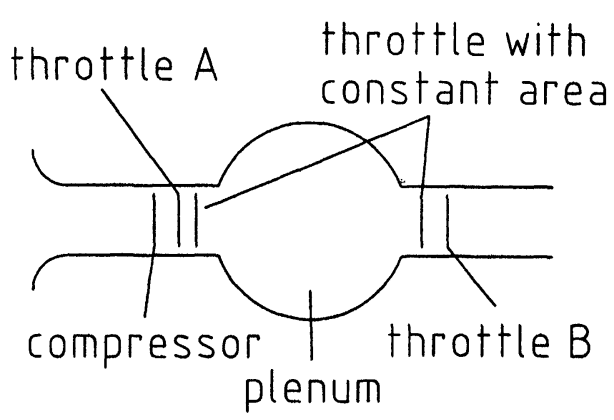

FIGURE 17 Complete model of the test stand.
It must be stressed that the compressor model represents only the given compressor. In order to estimate the transferability of the model, it has to be compared to the experimental data of other compressors.

\section{REAL-TIME STALL DETECTION}

The detection of unstable compressor operation is crucial for any stall control system. The data analysis algorithms should indicate unstable compressor operation in an as-early-as-possible state. At the same time they must not exceed the capabilities of the real-time processor applied for the control system. Both aspects were taken into account. This section describes algorithms with respect to their ability for detecting unstable compressor operation.

In Koenig et al. (1992); Wang et al. (1993, 1994, 1995) and Windirsch (1995), self-learning methods (Artificial Neural Networks, Vector Quantisation, etc.) are described that were applied for the realtime operating point estimation in the stable operating regime. For the application in the stall control system these methods have two drawbacks: (1) Intrusive measurement techniques should be avoided in the control system. (2) The operating point estimation is based on the detection of changes in the rotor wake as a result of operating point changes. However, when the compressor is operating near the limit of stability stall can evolve without any prior change of the operating point. In that case the above mentioned methods would fail.

Subsequently, non-intrusive measurement techniques and data analysis methods are described which were examined with respect to their ability for the real-time detection of unstable compressor operation. Three of the methods were found to be useful and will be applied in the control system.

\section{Measurement Techniques}

Microphone For the human perception, the compressor sound changes significantly with the 
operating point. This is particularly the case near the stability line. Therefore, a microphone was installed $0.5 \mathrm{~m}$ upstream of the compressor intake, and self-learning methods, as described in Section Data Analysis Methods, were applied to extract pre-stall indicators from the signal. Compared to the other signal sources examined, the microphone was not advantageous for the stall detection. Because of the many sources of sound at the test stand, the microphone signal was noisy and difficult to analyse. It was therefore found not to be useful for the control system.

Dynamic pressure probes In Section Transient Operation it was shown that upcoming stall can be seen at the compressor casing first. This allows the application of non-intrusive wall static pressure probes for the stall detection. For the data analysis methods subsequently described, an array of eight type-III probes was located at the positions $\mathrm{A} 1-\mathrm{A} 8$, and two additional type-II probes were located at the positions B2 and B8 (see Figs. 5 and 6).

\section{Data Analysis Methods}

Small amplitude travelling waves In Garnier et al. (1991), small-amplitude travelling waves in the compressor annulus are described which grow exponentially when the compressor operation becomes unstable. Thus, the wave amplitude can be used as a pre-stall indicator. Figure 18 shows the frequency power spectrum of one of the typeIII probes during stable operation near the stability line. The peak at a frequency of $30-50 \%$ of the rotor frequency is believed to originate from the waves described in Garnier et al. (1991). However, the waves could only be seen temporarily and therefore were not applicable for a continuously working stall monitoring system.

Self-learning algorithms A Perceptron as described in Cichocki and Unbehauen (1993) was applied to extract pre-stall indicators from the sensor signals. Fourier Transform and statistical methods were used for the preprocessing of the sampled data.

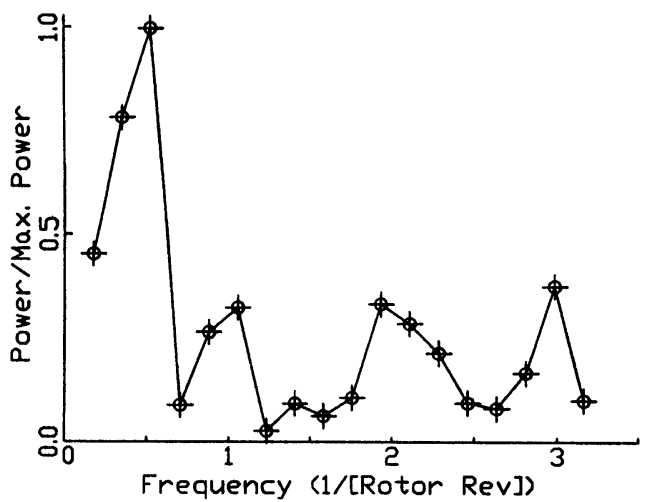

FIGURE 18 Power spectrum of a wall static pressure probe when the compressor operates near the stability line.

No pre-stall indicators could be extracted from the signals. Possible reasons are: (1) No useful information is contained in the signals. (2) The characteristics of the stall inceptions vary from case-to-case (e.g. the number of stall cells). Thus, the data base for the training of the Perceptron (data from 30 stall inceptions) was too small. (3) This type of the Artificial Neural Network and/or the preprocessing of the data was inappropriate.

Provisional result The results described above lead to the conclusion that at the examined compressor, unstable compressor operation cannot be detected before the actual onset of rotating stall. Three methods were found to be useful for the detection of upcoming stall in an early state:

Spatial Fourier Transform (SFT) The Fourier Transform was performed with respect to the circumferential location rather than the time. This method is described in Garnier et al. (1991). An array of eight type-III probes was located at the positions A1-A8 (see Figs. 5 and 6). When flow separations occur in the rotor, the potential effect of the blocking of the blade passage(s) lead to deflections of the upstream pressure signals which in turn can be identified in the Spatial Fourier Transform (SFT).

Figure 19 shows the pressure signal of one sensor, the power of the first circumferential harmonic, and the phase angle of the dominating pressure asymmetry in the annulus during stall inception. 


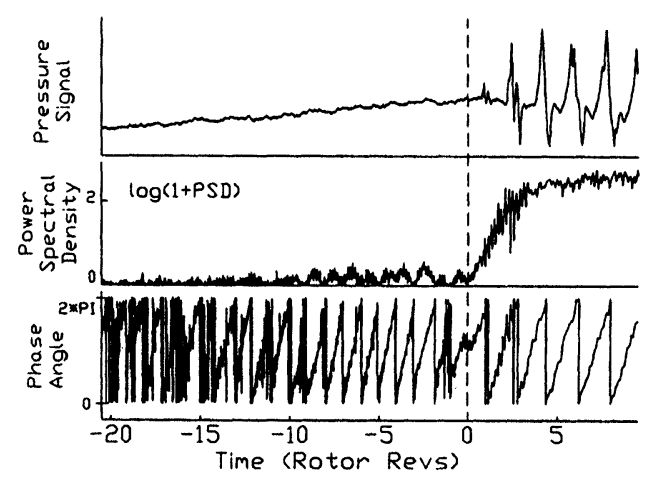

FIGURE 19 Power spectral density and phase angle of the first spatial harmonic of the pressure signals during stall inception.

Before stall, pressure fluctuations that rotate at rotor speed are dominant. As the compressor approaches the stability line, the fluctuations increase. It is yet to be examined whether the fluctuations can be used as stall margin indicators. As stall evolves, the stall cell clearly dominates the first circumferential harmonic. The power of that frequency sharply increases and can be used as an indicator for upcoming stall. During the evolution of the stall cell, the circumferential location and the cell size can be extracted from the data. This may become useful for the quantification of the capabilities of the stall control system.

The continuous deceleration of the stall cell in the absolute frame of reference (cf. Fig. 10) can be seen in the phase-vs-time plot only from the moment when the stall cell contributes the dominating pressure assymetry in the annulus $(t>0)$. Thus the phase-vs-time plot does not provide any information about the rotational speed of the stall cell during its very early state.

Short-time Fourier Transform (STFT) This method uses the correlation of the pressure signal in the vicinity of the rotor and a sine with the blade passing frequency. When flow separations occur in the rotor, the correlation vanishes. The correlation is obtained by a Fourier Transform of the pressure signal. To keep the response time short and the sensitivity high, short data windows (two blade passages) are analysed.

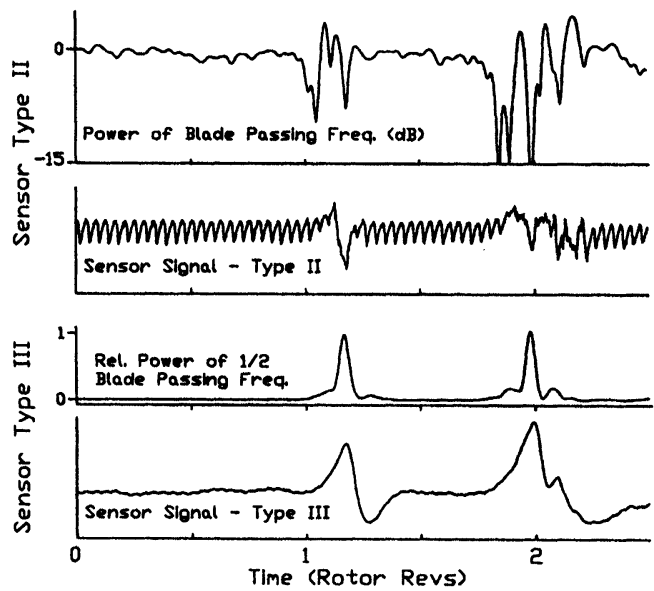

FIGURE 20 Comparison of the Short-time Fourier Transform with sensors type-II and type-III.

In the upper part of Fig. 20 the pressure signal of a type-II sensor in the location B2 (see Figs. 5 and 6) is shown as well as the corresponding spectral density of the blade passing frequency in the signal. Flow separations in the rotor lead to a significant drop of the spectral density which can be used as a stall indicator. One disadvantage of this method is the high response frequency and data sampling rate that is required to resolve the blade passing frequency.

Another way to apply the STFT is the correlation of the pressure signals with frequencies that exit when stall evolves. Due to the damping of the pressure pertubations upstream of the rotor and the growing of the stall cell, a wide range of frequencies below the blade passing frequency can be seen in the pressure signal during the evolution of stall. The feasibility of the STFT for the stall detection in conjunction with the type-III sensor was to be determined. In order to keep the response time short the pressure signal was correlated with half the blade passing frequency, which is near the maximum of what can be resolved with the typeIII sensors. In the lower part of Fig. 20 the pressure signal of a type-III sensor in the location A2 and the corresponding power of half the blade passing frequency is shown. At stall inception, the power increases. Compared to the upper part of that 
figure, the delay in the response of the power spectrum is short.

Compared to SFT, in STFT number and relative position of the sensors is irrelevant which may facilitate the application of such a method.

$A$ statistical method The method subsequently described can indicate stall in an earlier state than the STFT. It was chosen somewhat arbitrarily and is not based on a physical model of the compressor. As with STFT, each sensor signal can be analysed independently. Another advantage, with respect to real-time applications, is the small number of digital processor operations that is required for this method.

Two functions $f_{1}$ and $f_{2}$ are calculated from each sampled pressure value $p$ following the rule

$$
\frac{\mathrm{d}^{2} f_{i}}{\mathrm{~d} t^{2}}=\left(p-f_{i}\right) \cdot k_{i}-\frac{\mathrm{d} f_{i}}{\mathrm{~d} t} \cdot \mathrm{d}_{i}, \quad i=1,2 .
$$

Then the "area" $A$ which is enclosed by $f_{1}$ and $f_{2}$ is calculated as

$$
A=\int A+\left|f_{1}-f_{2}\right| \mathrm{d} t
$$

Whenever $f_{1}$ and $f_{2}$ intersect, $A$ is reset to zero. The functions $f_{1}$ and $f_{2}$ behave like band-pass filtered signals, $d_{1}$ and $d_{2}$ are adjusted in such manner, that no numerical instabilities occur, and $k_{1}$ and $k_{2}$ are set to values that for $f_{1}$ all the frequencies including and above the blade passing frequency are suppressed and for $f_{2}$ all frequencies including and above the rotor frequency respectively. A limit for $A$ can be found empirically so that it indicates upcoming stall when the limit is exceeded. Figure 21 shows the eight type-III sensor signals during stall inception. For each signal the point is shown where upcoming stall was detected first.

\section{ASPECTS OF THE IMPLEMENTATION OF ALGORITHMS ON A REAL-TIME COMPUTER}

A digital signal processor (DSP) is applied for the data aquisition, the data analysis, the digital

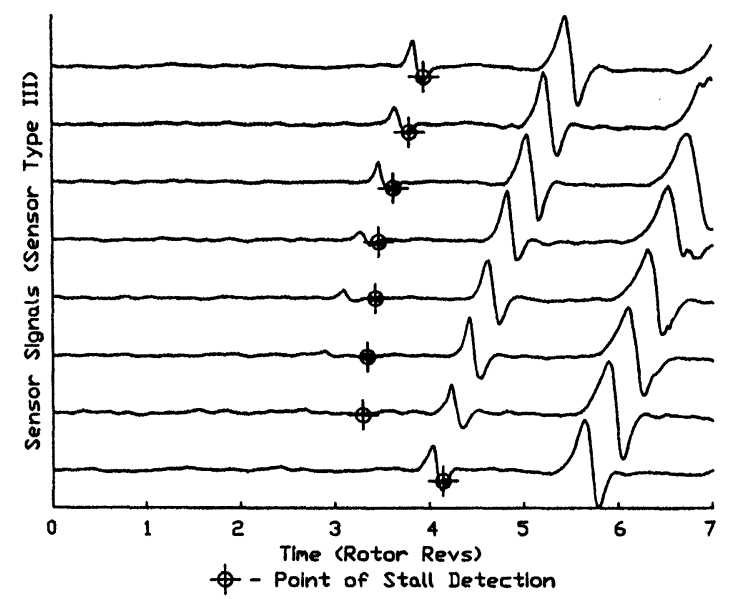

FIGURE 21 Locations of stall detection with the statistical method.

controller, and the operation of the step motor of the dynamic throttle. With respect to the technical feasibility as well as the schedule of the project it was found to be critical that the aspects of real-time computing are considered from a very early state of the project.

During the development of the control system, the cooperation with the Institute of Microelectronic Systems addresses new design flows to shorten the gap between algorithm exploration and the real-time implementation on a DSP. An interdisciplinary approach will facilitate designers to generate prototyping hardware without having detailed background in DSPs as well as low-level programming. Starting from the high-level specification of the algorithm, e.g. a C-description, the dataflow graphs are captured in a block-diagram based visual environment. After validating the processing requirement and correctness of the algorithm, C-code targeting specific commercial DSPs can be automatically generated, thus freeing the designer from the burden of low-level programming. Successive redesign and incremental changes to the system can be rapidly prototyped by just following the described design flow. 


\section{CONCLUSIONS}

The post-stall transients of a single-stage subsonic compressor were examined in detail as a basis for the design of an active stall avoidance system.

Models of the transient compressor response and the other components of the test stand were derived from the experimental data. They allow the simulation of the post-stall transients of the compression system.

The evolution time of rotating stall is approximately 10 rotor revolutions. In order to keep the control effort small and the operating point as steady as possible, the response time of a stall avoidance system must be well below this evolution time.

Although several measurement techniques and data analysis methods were applied, no indicators for unstable compressor operation prior to the onset of rotating stall could be found. Further investigations must be established to show whether rotor-synchronous pressure pertubations with varying strength can be used for the real-time estimation of the stall margin.

Three methods were described that allow the detection of upcoming stall in an early state of evolution. The implementation of the stall control system on real-time computers has been found to be critical for the project. In order to facilitate this step for system designers, a cooperation between the Department of Gas Turbines and Flight Propulsion and the Institute of Microelectronic Systems is established.

With respect to the stall control system under development, robust low-cost pressure transducers were found to be equivalent to surface-mounted microsensors.

\section{Acknowledgements}

This work was funded by Deutsche Forschungsgemeinschaft as part of the Special Research Program 241 Innovative Mechatronic Systems.

\section{NOMENCLATURE}

$\begin{array}{ll}\dot{m}_{\text {red }} & \begin{array}{l}\text { corrected mass flow } \\ p_{\mathrm{s}}\end{array} \\ p_{t 1}, p_{t 2} & \begin{array}{l}\text { wall static pressure } \\ \text { total pressure upstream, downstream } \\ \text { the compressor }\end{array} \\ \Phi & \begin{array}{l}\text { compressor flow coefficient }=\text { axial } \\ \text { velocity } / u\end{array} \\ \psi & \text { compressor pressure rise }= \\ & \left(p_{t 2}-p_{t 1}\right) /\left(\frac{1}{2} \cdot \rho u^{2}\right) \\ \psi_{\mathrm{s}} & \left(p_{\mathrm{s}}-p_{t 1}\right) /\left(\frac{1}{2} \cdot \rho u^{2}\right) \\ \rho & \text { density } \\ \text { PSD } & \text { Power spectral density } \\ t & \text { time in rotor revolutions } \\ u & \text { rotor speed at mid-span }\end{array}$

\section{References}

Cichocki, A. and Unbehauen, R. (1993) Neural Networks for Optimization and Signal Processing, John Wiley \& Sons Ltd. \& B.G. Teubner, Stuttgart.

Garnier, V.H., Epstein, A.H. and Greitzer, E.M. (1991) Rotating waves as a stall inception indication in axial compressors, Journal of Turbomachinery, 113, 290-302.

Greitzer, E.M. (1976) Surge and rotating stall in axial flow compressors, Part I: Theoretical compression system model, Journal of Engineering for Power, 98, 190-198.

Koenig, A. et al. (1992) An approach to the application of neural networks for real-time operating point estimation in turbojet compressor units, Proc. IJCNN-'92, Beijing, China, Vol. III, pp. $63-69$.

Wang, H. and Hennecke, D.K. (1993) Ein Beitrag zur StallErkennung im Verdichter unter Echtzeitbedingungen, VDI Fortschritt-Berichte Nr. 179, pp. 107-115.

Wang, H. and Hennecke, D.K. (1994) Grundlagenorientierte experimentelle Untersuchungen der Stallerkennung im Verdichter unter Echtzeitbedingungen, VDI Berichte $\mathrm{Nr}$. 1109 , pp. 681-702.

Wang, H. et al. (1993) An approach to the stall monitoring in a single stage axial compressor, Proc. AIAA/SAE/ASME/ ASEE 29th Joint Propulsion Conference and Exhibit, No. AIAA-93-1872.

Wang, H. et al. (1995) Method for estimating various operating states in a single-stage axial compressor, Journal of Propulsion and Power, 11(2), 385-387.

Windirsch, P. (1995) Entwurf anwendungsspezifischer, integrierter Schaltungen für den Einsatz in der Mechatronik, Darmstadt University of Technology. 


\section{ait \\ ENERGY MATERIALS}

M A N E Y publishing

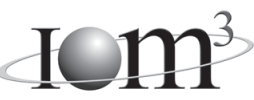

\section{Materials Science \& Engineering for Energy Systems}

Maney Publishing on behalf of the Institute of Materials, Minerals and Mining

The Institute of Materials, Minerals \& Mining

Economic and environmental factors are creating ever greater pressures for the efficient generation, transmission and use of energy. Materials developments are crucial to progress in all these areas: to innovation in design; to extending lifetime and maintenance intervals; and to successful operation in more demanding environments. Drawing together the broad community with interests in these areas, Energy Materials addresses materials needs in future energy generation, transmission, utilisation, conservation and storage. The journal covers thermal generation and gas turbines; renewable power (wind, wave, tidal, hydro, solar and geothermal); fuel cells (low and high temperature); materials issues relevant to biomass and biotechnology; nuclear power generation (fission and fusion); hydrogen generation and storage in the context of the 'hydrogen economy'; and the transmission and storage of the energy produced.

As well as publishing high-quality peer-reviewed research, Energy Materials promotes discussion of issues common to all sectors, through commissioned reviews and commentaries. The journal includes coverage of energy economics and policy, and broader social issues, since the political and legislative context influence research and investment decisions.

\section{CALL FOR PAPERS}

Contributions to the journal should be submitted online at http://ema.edmgr.com

To view the Notes for Contributors please visit: www.maney.co.uk/journals/notes/ema

Upon publication in 2006, this journal will be available via the Ingenta Connect journals service. To view free sample content online visit: www.ingentaconnect.com/content/maney

For further information please contact:

Maney Publishing UK

Tel: +44 (0)113 2497481 Fax: +44 (0)1132486983 Email: subscriptions@maney.co.uk

or

Maney Publishing North America

Tel (toll free): 8662975154 Fax: 6173546875 Email: maney@maneyusa.com

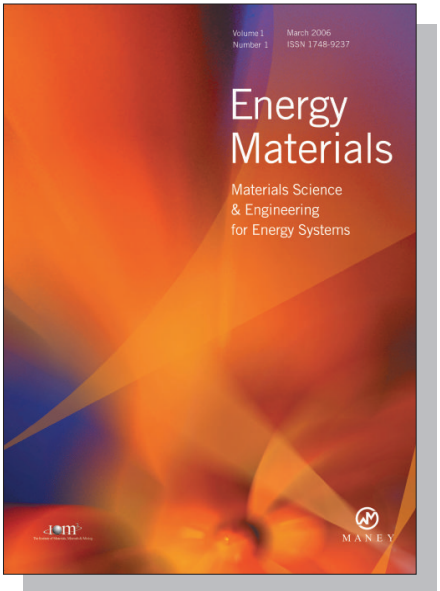

EDITORS

Dr Fujio Abe

NIMS, Japan

Dr John Hald, IPL-MPT, Technical University of Denmark, Denmark

Dr R Viswanathan, EPRI, USA

\section{SUBSCRIPTION INFORMATION}

Volume 1 (2006), 4 issues per year

Print ISSN: 1748-9237 Online ISSN: 1748-9245

Individual rate: $£ 76.00 / U S \$ 141.00$

Institutional rate: $£ 235.00 /$ US $\$ 435.00$

Online-only institutional rate: $£ 199.00 / U S \$ 367.00$

For special $\mathrm{IOM}^{3}$ member rates please email

subscriptions@maney.co.uk

\section{For further information or to subscribe online please visit www.maney.co.uk}



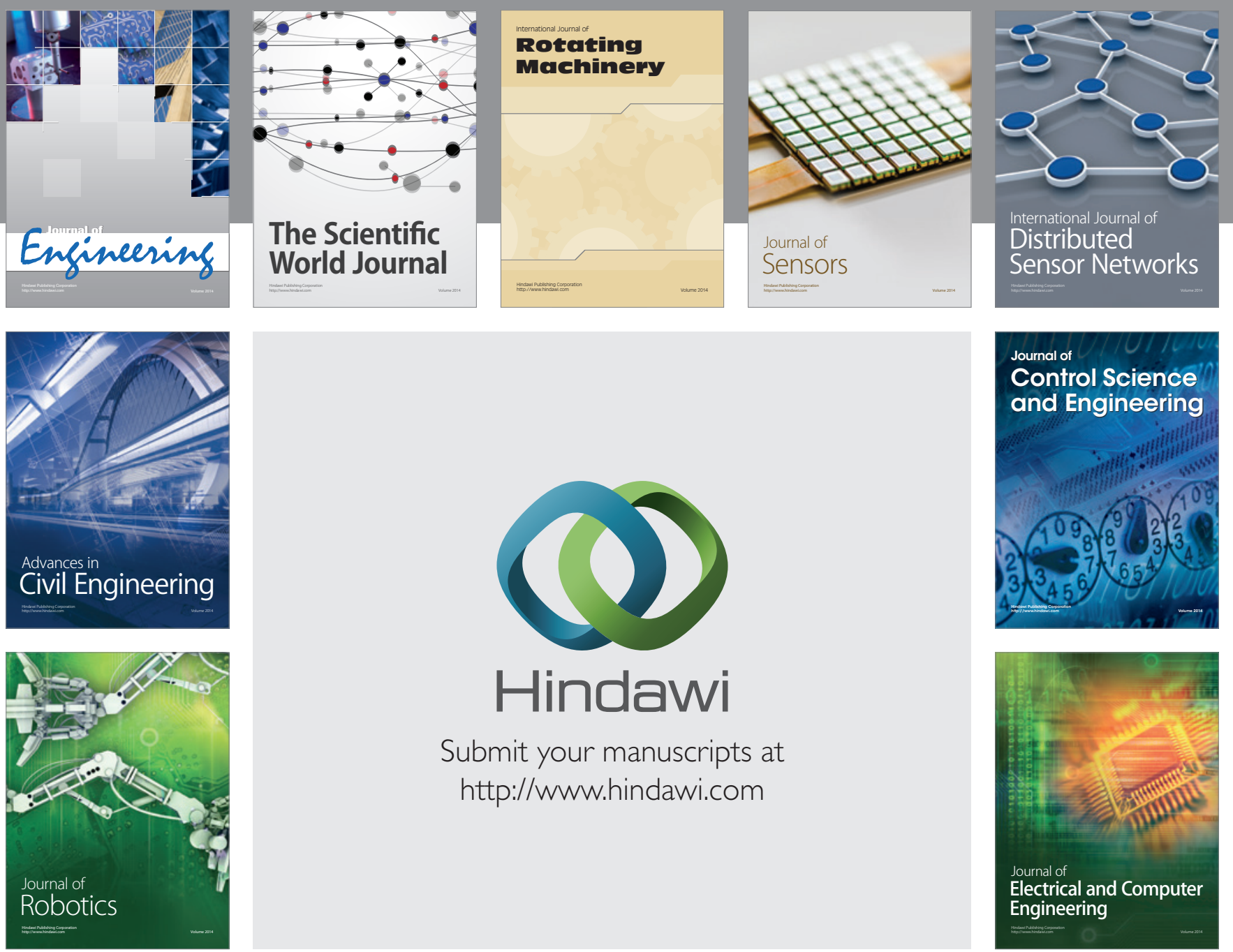

Submit your manuscripts at

http://www.hindawi.com
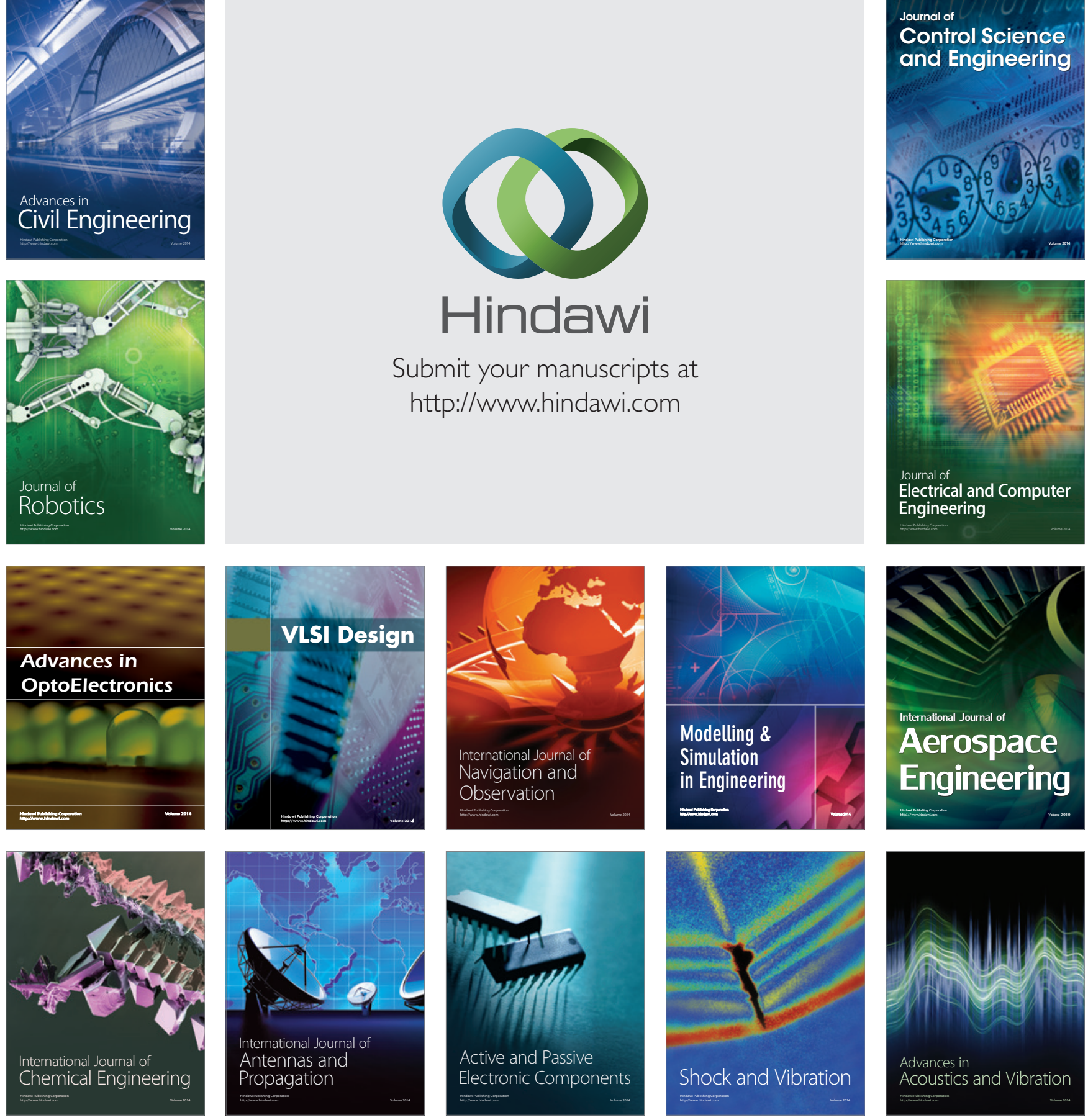